\title{
"Heart without smoke" educational campaign the role of patient education in secondary prevention of cardiovascular disease
}

\author{
Zbigniew Siudak $^{1,2, *}$, Agata Krawczyk-Ożóg ${ }^{1, *}$, Iwona Twarda ${ }^{3}$, Iwona Franczak ${ }^{3}$, Renata Rajtar-Salwa ${ }^{1}$, \\ Stanisław Bartuś ${ }^{1}$, Jacek Godlewski ${ }^{3}$, Dariusz Dudek ${ }^{1,2}$ \\ $12^{\text {nd }}$ Department of Cardiology and Cardiovascular Interventions, University Hospital, Krakow, Poland \\ 2Department of Interventional Cardiology, Jagiellonian University Medical College, Krakow, Poland \\ ${ }^{3}$ Centre for Invasive Cardiology, Angiology and Electrotherapy, Pinczow, Poland \\ *Equal contribution
}

\begin{abstract}
Background: Nicotine addiction is the strongest factor in the increase of the risk of recurrent ischaemic events.

Aim: The aim of the study was to analyse the effectiveness of a smoking cessation educational programme in a population of patients hospitalised with acute myocardial infarction within the "Heart without smoke" campaign.

Methods: In this study, we included 100 consecutive patients, active smokers, hospitalised with acute myocardial infarction (STEMI or NSTEMI) at the Centre for Invasive Cardiology, Angiology, and Electrotherapy in Pinczow, Poland in the period from January to December 2015 (12 months). Patients were participants in the educational campaign about tobacco addiction "Heart without smoke".

Results: At one-month follow-up observation: 61 patients had quit smoking and an additional 35 had decreased the number of cigarettes smoked per day. During six-month follow-up interview: 51 patients did not smoke cigarettes (13 had returned to smoking, three had additionally stopped smoking, one person had died). There were no statistically significant correlations between smoking cessation and gender $(p=0.4 ; p=0.2)$, age $(p=0.8 ; p=0.8)$ and length of prior smoking habit $(p=0.8$; $p=0.5)$ and daily cigarette consumption before myocardial infarctions $(p=0.3 ; p=0.3)$, one month, and six months after hospital discharge, respectively.

Conclusions: Constant education of patients after myocardial infarction was an effective method for smoking cessation in over $50 \%$ of smokers six months after myocardial infarction.
\end{abstract}

Key words: nicotine, tobacco smoking, secondary prevention, myocardial infarction, educational campaign

Kardiol Pol 2018; 76, 1: 125-129

\section{INTRODUCTION}

Secondary prevention of cardiovascular disease (CVD) aims to prevent the recurrence of cardiovascular events, e.g. myocardial infarction (MI) in patients already diagnosed with CVD. It involves the optimal pharmacotherapy and modification of the risk factors, understood as lifestyle changes in the area of physical activity, diet, and addiction habits like smoking. Tobacco smoking is a primary factor of premature death, cancer, respiratory disease, as well as coronary artery disease occurrence [1, 2]. Smoking status is a basic variable in almost all current CVD risk estimation scores for use in apparently healthy persons, next to sex, age, total cholesterol, high-density lipoprotein cholesterol, systolic blood pressure, diabetes mellitus, and hypertensive treatment. Nicotine addiction is the strongest factor in the increase of the risk of recurrent ischaemic events [3]. A person who is an active smoker has a $50 \%$ probability of dying due to smoking, and on average will lose 10 years of life [4]. It is much more than for

\section{Address for correspondence:}

Zbigniew Siudak, MD, PhD, Department of Interventional Cardiology, University Hospital, ul. Kopernika 17, 31-501 Kraków, Poland, tel: +48 124247181 , fax: +48 1242471 84, e-mail: zbigniew.siudak@gmail.com

Received: 14.04.2017 Accepted: 20.07.2017 Available as AoP: 21.08.2017

Kardiologia Polska Copyright (c) Polskie Towarzystwo Kardiologiczne 2018 
other risk factors, e.g. the occurrence of severe hypertension leads to three years loss of life, and mild hypertension about one year [5]. In the last three decades, more than half of the decrease in CVD mortality has been attributed to reduction in cholesterol and blood pressure levels, but also smoking. European Society of Cardiology guidelines on CVD prevention emphasise that risk factor goals and target levels are no exposure to tobacco in any form, which means complete cessation [3]. Based on data from the Polish WOBASZ II study, in Poland $30 \%$ of men and $21 \%$ of women smoke, the shares being $9 \%$ and $4 \%$ lower for men and women, respectively, in comparison with the first WOBASZ study $(p<0.001)$ [6]. The NATPOL 2011 study indicated a comparable number of smoking men (31.5\%), more women $(27.5 \%)$, and showed a decrease in the prevalence of smoking for both genders in the period from 2001 to 2011 [7]. A promising observation is that since 2003 Polish adults significantly advanced their cardiovascular health knowledge about risk factors [8]. New data on the epidemiology of smoking in the Polish population show that the prevalence in men is $31 \%$ and in women $18 \%$, which is still higher compared to Western European countries [9]. In the Polish part Global Adult Tobacco Survey in the years 2009 to 2010, reported socio-demographic factor correlates of daily cigarette smoking are: lower educational level, unemployment, living in urban areas, and age between 20 and 59 years [10]. The World Health Organisation revealed that the number of deaths associated with smoking-related diseases exceeded 100 million in the $20^{\text {th }}$ century [11]. In Poland, every year approximately 70,000 people die as a result of smoking $[12,13]$. Quitting smoking is associated with $36 \%$ risk reduction of all-cause mortality among patients with CVD and is substantial compared with other secondary preventive therapies such as cholesterol lowering and standard pharmacotherapy [14]. The AHA/ACCF Secondary Prevention and Risk Reduction Therapy for Patients with Coronary and Other Atherosclerotic Vascular Disease recommend that patients should be asked about smoking status and advised at every office visit. Additionally, patients should be assisted by medical personnel by helping them create a plan for quitting [15]. The help could concentrate solely on pharmacotherapy, but one cannot forget about patient participation in smoking cessation social campaigns or programmes that address the issue. Nowadays, these kinds of programmes are created and propagate among patients, and their results are promising [16]. An intensive smoking-cessation intervention programme is more effective than a stepped-care approach [17], but data show that fewer than $20 \%$ of smokers had used any recommended aid to quitting smoking. People in countries with developed tobacco cessation programmes have increased likelihood of using efficacious cessation aids [18]. Thus, expansion of smoking cessation aid that induces and maintains long-term smoking quitting in patients is required.
The aim of the study is to analyse the effectiveness of a smoking cessation educational programme in a population of patients hospitalised with acute myocardial infarction (AMI) within the "Heart without smoke" campaign.

\section{METHODS}

A total of 100 consecutive patients, active smokers, were enrolled to the study. Patients were hospitalised with AMI (STEMI or NSTEMI) at the Centre for Invasive Cardiology, Angiology, and Electrotherapy in Pinczow, Poland in the period from January to December 2015 (12 months). Patients were participants in the educational campaign about tobacco addiction "Heart without smoke". At the time of hospital discharge and one and six months after discharge, dedicated nursing staff educated patients about the dangers of smoking and presented possibilities for support in smoking cessation and about tobacco addiction pharmacological treatment, usually in the presence of patient family and/or relatives upon prior patient approval. During hospital discharge (usually 4-6 days after percutaneous coronary intervention [PCI]) a dedicated and trained nurse provided at least 10 min talk with each patient. He/she also called patients on the phone at one and six months and advised them on the benefits of smoking cessation as well as reminding them of the possible options, and invited them to consult the cardiologist at the department if required. The nurses were trained in Krakow by cardiologists from the Institute of Cardiology at Jagiellonian University during a dedicated meeting as well as on-site in the Department in Pinczow before the start of the campaign. Physicians were informed of the campaign and provided an additional talk with each patient at discharge. Additionally, patients were provided with printed educational materials and a campaign dedicated website (www.sercebezdymu.pl) on discharge and a dedicated phone number of the physician whenever they wished to consult their smoking habit. Each discharge letter contained information on the campaign website. A study-dedicated nurse filled out a questionnaire that collected data on the history of smoking, daily tobacco consumption, current tobacco use status, etc. Furthermore, demographics, baseline characteristics, and medical history data were collected from medical history.

In this study, we included 100 patients of both sexes $(80 \%$ men) with a mean age of $60.5 \pm 8.9$ years. Demographic and past medical history details are presented in Table 1.

\section{Statistical analysis}

The data are presented as mean values and the corresponding standard deviations. Categorical variables were presented as percentages. The Shapiro-Wilk test was used to determine if the quantitative data were normally distributed. Correlation coefficients were calculated to measure the statistical dependence between the measured parameters. We performed 
Table 1. Patient baseline demographics and past medical history $(\mathrm{n}=100)$

\begin{tabular}{lc|} 
Variable & $\%$ or mean \pm SD \\
\hline Age & $60.5 \pm 8.9$ \\
Males & $80 \%$ \\
Heart failure & $14 \%$ \\
Previous Ml & $8 \%$ \\
Hypertension & $51 \%$ \\
Diabetes mellitus & $20 \%$ \\
COPD & $13 \%$ \\
Overweight with BMI > $25 \mathrm{~kg} / \mathrm{m}^{2}$ & $17 \%$ \\
Obese with BMI > 30 kg/m² & $12 \%$ \\
Retirement & $58 \%$ \\
Time of active smoking [years] & $34.9 \pm 11.0$ \\
No. of cigarettes per day & $20.1 \pm 9.9$ \\
\hline
\end{tabular}

BMI - body mass index; COPD — chronic obstructive pulmonary disease; MI - myocardial infarction; SD — standard deviation

Table 2. The results of preventive intervention of the "Heart without smoke" educational campaign on smoking cessation in follow-up observation

\begin{tabular}{|lcc|} 
& Non- & $\mathbf{p}$ \\
& -smokers & \\
\hline At hospital discharge & 0 & - \\
One-month after discharge & 61 & $<0.001$ \\
Six-months after discharge & 51 & 0.154 \\
\hline
\end{tabular}

statistical analyses with STATISTICA v12 (StatSoft Inc., Tulsa, OK, USA). A p-value of less than 0.05 was considered to be statistically significant.

\section{RESULTS}

In the analysed group, 34 patients tried to quit smoking ineffectively before being admitted to hospital for AMI, and 54 patients quit smoking only for short period of time (less than three months). Among these 5\% used chewing gums or transdermal nicotine patches, $6 \%$ used electronic cigarettes,
$11 \%$ various type of medications, and $78 \%$ did not use any kind of help in smoking cessation. The majority of the patients (86\%) had never asked a doctor or been given advice about possible smoking cessation interventions. After the "Heart without smoke" educational campaign, at one-month follow-up 61 patients had quit smoking and an additional 35 had decreased the number of cigarettes smoked per day. During a six-month follow-up interview, 51 patients did not smoke cigarettes (13 had returned to smoking, three had additionally stopped smoking, one had person died; Table 2). There were no correlations between smoking cessation and gender $(p=0.4 ; p=0.2)$, age $(p=0.8 ; p=0.8)$, duration of smoking $(p=0.8 ; p=0.5)$, and daily cigarette consumption $(p=0.3 ; p=0.3$ ) one month and six months after hospital discharge, respectively. Table 3 shows detailed results of using nicotine replacement therapy or electronic cigarettes.

During six-month observation after index hospital stay all patients had stable angina class 1 or 2 and one patient died (cause of death unknown). An additional 10 patients had elective hospitalisations concerning their CVD (elective PCls). No differences between smokers vs. non-smokers were observed $(p>0.05)$.

\section{DISCUSSION}

Patients after $\mathrm{MI}$ are intensely motivated to quit smoking when discharged from hospital. These motivations decrease with the passage of time because they are not sustained in everyday life. In this study, more than half of the patients had participated in an educational campaign about quitting smoking addiction in six-month follow-up after MI. Higher educational level, not living with a smoker, following a multimodal programme or smoking cessation with psychological therapy, and pharmacological treatment are relevant factors for quitting smoking [19]. Some of these factors are independent. Nevertheless, initiation and promotion by medical staff educational programmes increased the smoking cessation rates for hospitalised patients [20, 21]. Although the six-month effectiveness of short medical advice is estimated to be $2-3 \%$, in each visit every smoking patient should be advised to quit smoking by a doctor or other medical staff member, with underlined medical risks related to smoking.

Table 3. The results of using nicotine replacement therapy or electronic cigarettes by patients one and six month after discharge from hospital. In the smoking group there were patients who ineffectively tried to use nicotine replacement therapy or electronic cigarettes

\begin{tabular}{|llccc|} 
& & Smokers & No-smokers & $\mathbf{p}$ \\
\hline \multirow{5}{*}{ One-month after discharge } & Pharmacotherapy, gums, nicotine patches & 5 & 2 & 0.098 \\
& Electronic cigarettes & 2 & 0 & 5 \\
& Nothing & 32 & 59 & 0.004 \\
& Pharmacotherapy, gums nicotine patches & 12 & 2 & 0 \\
& Electronic cigarettes & 3 & 49 & 33 \\
& Nothing & 33 & & \\
\hline
\end{tabular}


Periodic telephone contact to provide a useful guideline for behaviour during the period of cessation, and social support, are especially effective [9]. Meta-analysis results indicate that intensive individual counselling by a physician increases the probability of permanent cessation of smoking by $84 \%$, and by a nurse by $28 \%$ [22]. The effect of an educational campaign could increase in cases with cooperation with patients' close family or household members. Park et al. [23] suggested that nurses' contact supporting smoking cessation (phone or SMS messages) reduces the prevalence of smoking and increases the health-promoting lifestyle changes in patients, who undergo $\mathrm{PCl}$. Additionally, personalised interventions are feasible and acceptable by patients [23]. Published studies indicate that the introduction or intensification of smoking bans in public places is associated with reduced number of hospitalisations due to MI [24]. Nowadays there are websites offering smoking cessation support, but there is not much proof for their effectiveness [25]. These programmes could be created by unprofessional persons and characterise a lack of participant control, misunderstanding, and what is worse the promotion of electronic cigarettes. Electronic cigarettes (e-cigarettes) may help people to quit smoking, and probably they are healthier, because they contain nicotine without the vast majority of tobacco chemicals [26]. There is no strong evidence proving the effectiveness of e-cigarettes in quitting cigarettes [27]. In our study, there were two patients who used electronic cigarettes before admission to hospital and a few after MI. The safety of this way to deliver nicotine is under investigation. There are no long-term observations and the side effects are unknown, although electronic cigarettes are less harmful than conventional smoking [26]. Nicotine replacement therapy was not so popular in the analysed group of patients. Probably this is caused by the place of residence (a small city of less than 12,000 residents) and doubts about safety concerning the pharmacotherapy. There is no doubt that smokeless tobacco in comparison to conventional smoking is also associated with a small but statistically significant increased risk of $\mathrm{Ml}$ and stroke [3]. Pre-discharge standard education alone after $\mathrm{MI}$ is not enough in patients with strong, long-term addiction. Small amount of qualified staff, and lack of time and funds leads to abandonment or minimisation of patient education. Introduction of dedicated staff and a constant educational campaign could solve these problems and have an impact on the increased amount of successful smoking cessations. The personalised instructions about how to change behaviour to stop smoking, and follow-up of patients, is crucial in order to achieve permanent and satisfactory results.

\section{Limitations of the study}

The results of the present study were obtained at only one centre with no control group for comparison. There were only 100 patients in the study; however, these were real consecutive ones. Additionally, no objective measures of nicotine addiction such as urine cotinine levels were used in the study due to logistic and financial restrictions. The degree of addiction, commonly assessed by the Fagerstrom test [28], was not assessed, which could expand the interpretation of obtained results.

\section{CONCLUSIONS}

Constant education of patients after $\mathrm{MI}$ was an effective method for smoking cessation in over $50 \%$ of smokers six months after MI. The majority of smokers did not receive any form of advice on smoking cessation before the index hospitalisation for MI. All patients with CVD, especially after MI, should receive support to prevent a subsequent event, within the secondary preventive interventions. The role of nursing staff in the support the maintenance of smoking cessation decisions is important and essential in daily practice for all healthcare providers.

\section{Conflict of interest: none declared}

\section{References}

1. ITC Project, World Health Organization, World Heart Federation. Cardiovascular harms from tobacco use and secondhand smoke: Global gaps in awareness and implications for action. Waterloo, Ontario, Canada and Geneva, Switzerland. 2012.

2. WHO global report: mortality attributable to tobacco. Geneva, World Health Organization. 2012.

3. Piepoli MF, Hoes AW, Agewall S, et al. 2016 European Guidelines on cardiovascular disease prevention in clinical practice: The Sixth Joint Task Force of the European Society of Cardiology and Other Societies on Cardiovascular Disease Prevention in Clinical Practice (constituted by representatives of 10 societies and by invited experts)Developed with the special contribution of the European Association for Cardiovascular Prevention \& Rehabilitation (EACPR). Eur Heart J. 2016; 37(29): 2315-2381, doi: 10.1093/eurheartj/ehw106, indexed in Pubmed: 27222591.

4. Doll R, Peto R, Boreham J, et al. Mortality in relation to smoking: 50 years' observations on male British doctors. BMJ. 2004; 328(7455): 1519, doi: 10.1136/bmj.38142.554479.AE, indexed in Pubmed: 15213107.

5. Kiiskinen U, Vartiainen E, Puska P, et al. Long-term cost and life-expectancy consequences of hypertension. J Hypertens. 1998; 16(8): 1103-1112, indexed in Pubmed: 9794712.

6. Polakowska M, Kaleta D, Piotrowski W, et al. Tobacco smoking in Poland in the years from 2003 to 2014. Multi-centre National Population Health Examination Survey (WOBASZ). Pol Arch Intern Med. 2017; 127(2): 91-99, doi: 10.20452/pamw.3896, indexed in Pubmed: 28224973.

7. Kopeć G, Jankowski P, Pająk A. , et al. Epidemiology and prevention of cardiovascular diseases. Medycyna Praktyczna, Kraków, Poland 2015.

8. Piwońska A, Piotrowski W, Piwoński J, et al. Cardiovascular health knowledge of the Polish population. Comparison of two national multi-centre health surveys: WOBASZ and WOBASZ II. Kardiol Pol. 2017; 75(7): 711-719, doi: 10.5603/KP.a2017.0070, indexed in Pubmed: 28394004.

9. Jankowski P, Kawecka-Jaszcz K, Kopeć G, et al. Polish Forum for Prevention Guidelines on Smoking: update 2017. Kardiol Pol. 2017; 75(4): 409-411, doi: 10.5603/KP.2017.0066, indexed in Pubmed: 28421582. 
10. Kaleta D, Makowiec-Dą̧browska T, Dziankowska-Zaborszczyk E, et al. Prevalence and socio-demographic correlates of daily cigarette smoking in Poland: results from the Global Adult Tobacco Survey (2009-2010). Int J Occup Med Environ Health. 2012; 25(2): 126-136, doi: 10.2478/S13382-012-0016-8, indexed in Pubmed: 22447036.

11. WHO global report on trends in prevalence of tobacco smoking 2015. Geneva: World Health Organization. 2015.

12. World Health Organization (WHO). The current status of the tobacco epidemic in Poland. Copenhagen: World Health Organization. 2009.

13. Oberg M, Jaakkola MS, Woodward A, et al. Worldwide burden of disease from exposure to second-hand smoke: a retrospective analysis of data from 192 countries. Lancet. 2011; 377(9760): 139-146, doi: 10.1016/S0140-6736(10)61388-8, indexed in Pubmed: 21112082.

14. Critchley J, Capewell S. Smoking cessation for the secondary prevention of coronary heart disease. Cochrane Database Syst Rev. 2004(1):CD003041, doi: 10.1002/14651858.CD003041.pub2, indexed in Pubmed: 14974003.

15. Smith SC, Benjamin EJ, Bonow RO, et al. AHA/ACCF Secondary Prevention and Risk Reduction Therapy for Patients with Coronary and other Atherosclerotic Vascular Disease: 2011 update: a guideline from the American Heart Association and American College of Cardiology Foundation. Circulation. 2011; 124(22): 2458-2473, doi: 10.1161/CIR.0b013e318235eb4d, indexed in Pubmed: 22052934.

16. FreeC, Knight R, Robertson S, et al. Smoking cessation support delivered via mobile phone text messaging (txt2stop): a single-blind, randomised trial. Lancet. 2011; 378(9785): 49-55, doi: 10.1016/S01406736(11)60701-0, indexed in Pubmed: 21722952.

17. Smith PM, Burgess E. Smoking cessation initiated during hospital stay for patients with coronary artery disease: a randomized controlled trial. CMAJ. 2009; 180(13): 1297-1303, doi: 10.1503/cmaj.080862, indexed in Pubmed: 19546455.

18. Filippidis FT, Gerovasili V, Vardavas CI, et al. Determinants of use of smoking cessation aids in 27 European countries. Prev Med. 2014; 65: 99-102, doi: 10.1016/j.ypmed.2014.05.004, indexed in Pubmed: 24832820.
19. Raich A, Martínez-Sánchez JM, Marquilles E, et al. Smoking cessation after 12 months with multi-component therapy. Adicciones. 2015; 27(1): 37-46, indexed in Pubmed: 25879476.

20. Clay CM, Dyer AR, Liu K, et al. Education, smoking and non-cardiovascular mortality: findings in three Chicago epidemiological studies. Int J Epidemiol. 1988; 17(2): 341-347, indexed in Pubmed: 3403129.

21. Taylor CB, Miller NH, Herman S, et al. A nurse-managed smoking cessation program for hospitalized smokers. Am J Public Health. 1996; 86(11): 1557-1560, indexed in Pubmed: 8916520.

22. Zdrojewski T, Jankowski P, Bandosz P, et al. [A new version of cardiovascular risk assessment system and risk charts calibrated for Polish population]. Kardiol Pol. 2015; 73(10): 958-961, doi: 10.5603/KP.2015.0182, indexed in Pubmed: 26521843

23. Park AiH, Lee SJ, Oh SJ. The effects of a smoking cessation programme on health-promoting lifestyles and smoking cessation in smokers who had undergone percutaneous coronary intervention. Int J Nurs Pract. 2015; 21(2): 107-117, doi: 10.1111/ijn.12230, indexed in Pubmed: 25860913.

24. Jankowski P, Kawecka-Jaszcz K, Jassem J, et al. [Why the ban on smoking should be expanded in Poland?]. Kardiol Pol. 2009; 67(1): 101-105, indexed in Pubmed: 19253200.

25. Feil EG, Noell J, Lichtenstein Ed, et al. Evaluation of an Internet-based smoking cessation program: lessons learned from a pilot study. Nicotine Tob Res. 2003; 5(2): 189-194, doi: 10.1080/1462220031000073694, indexed in Pubmed: 12745491.

26. Pisinger C, Døssing M. A systematic review of health effects of electronic cigarettes. Prev Med. 2014; 69: 248-260, doi: 10.1016/j. ypmed.2014.10.009, indexed in Pubmed: 25456810.

27. McRobbie H, Bullen C, Hartmann-Boyce J, et al. Electronic cigarettes for smoking cessation and reduction. Cochrane Database Syst Rev. 2014(12): CD010216, doi: 10.1002/14651858. CD010216.pub2, indexed in Pubmed: 25515689.

28. Heatherton TF, Kozlowski LT, Frecker RC, et al. The Fagerström Test for Nicotine Dependence: a revision of the Fagerström Tolerance Questionnaire. Br J Addict. 1991; 86(9): 1119-1127, indexed in Pubmed: 1932883.

Cite this article as: Siudak Z, Krawczyk-Ożóg A, Twarda I, et al. "Heart without smoke" educational campaign — the role of patient education in secondary prevention of cardiovascular disease. Kardiol Pol. 2018; 76(1): 125-129, doi: 10.5603/KP.a2017.0167. 